\title{
Prenatal and postnatal psychological symptoms of parents and family functioning: the impact on child emotional and behavioural problems
}

\author{
Fleur P. Velders $\cdot$ Gwen Dieleman $\cdot$ Jens Henrichs \\ Vincent W. V. Jaddoe $\cdot$ Albert Hofman - Frank C. Verhulst • \\ James J. Hudziak $\cdot$ Henning Tiemeier
}

Received: 31 August 2010/Accepted: 13 April 2011/Published online: 27 April 2011

(C) The Author(s) 2011. This article is published with open access at Springerlink.com

\begin{abstract}
Although relations of various parental psychological problems and family functioning with child development are well documented, it remains unclear whether specific prenatal or specific postnatal risk factors are independently associated with child emotional and behavioural problems, or whether observed associations can be explained
\end{abstract}

Electronic supplementary material The online version of this article (doi:10.1007/s00787-011-0178-0) contains supplementary material, which is available to authorized users.

F. P. Velders · G. Dieleman - F. C. Verhulst .

J. J. Hudziak · H. Tiemeier $(\square)$

Department of Child and Adolescent Psychiatry, Erasmus

Medical Center, Sophia Children's Hospital, P.O. Box 2060,

3000 CB Rotterdam, The Netherlands

e-mail: h.tiemeier@erasmusmc.nl

F. P. Velders · J. Henrichs · V. W. V. Jaddoe

The Generation R Study Group, Erasmus MC University

Medical Center, Rotterdam, The Netherlands

V. W. V. Jaddoe · A. Hofman · H. Tiemeier

Department of Epidemiology, Erasmus MC University Medical

Center, Rotterdam, The Netherlands

\section{J. Henrichs}

Institute of Psychology, Erasmus University Rotterdam,

Rotterdam, The Netherlands

V. W. V. Jaddoe

Department of Pediatrics, Erasmus Medical Center,

Sophia Children's Hospital, Rotterdam, The Netherlands

J. J. Hudziak

Departments of Psychiatry, Medicine and Pediatrics, College

of Medicine, University of Vermont, Burlington, VT, USA

J. J. Hudziak

Department of Biological Psychology, Vrije Universiteit,

Amsterdam, The Netherlands by general parental psychopathology. Using a stepwise approach, we examined the effects of prenatal and postnatal parental depressive symptoms, prenatal and postnatal hostility of the parents, as well as prenatal family functioning on the risk of child emotional and behavioural problems. This study was embedded in Generation R: a population-based cohort from foetal life onwards. Mothers and fathers of 2,698 children provided information about depressive symptoms, symptoms of hostility and family functioning during pregnancy and 3 years after birth. Mother and father each reported on child behaviour when the child was 3 years old. Parental depressive symptoms increased the risk of child emotional and behavioural problems, but this increase was explained by postnatal parental hostile behaviour. Postnatal symptoms of hostility of mothers $(\mathrm{OR}=1.34$, $p$ value $<0.001)$ and postnatal symptoms of hostility of fathers $(\mathrm{OR}=1.30, p$ value $<0.001)$ each contributed independently to the risk of child emotional and behavioural problems. Postnatal parental hostility is associated with an increased risk of child emotional and behavioural problems, independent of parental depressive symptoms. These findings suggest that prevention and intervention strategies should focus on psychological symptoms of both mothers and fathers, in particular on hostile behaviour, in families with young children.

Keywords Family functioning - Psychopathology . Depression · Hostility · Child emotional and behavioural problems

\section{Introduction}

A broad range of psychological problems of parents places children at risk for the development of emotional and 
behavioural problems. A key example is the effect of maternal depression on child development. Not only is depression in children of depressed mothers more frequent and more severe than in children of non-depressed mothers, but these children also display more anxiety disorders, aggression, attention deficits, insecure attachment, poor self-esteem and poor peer relations [1,2]. The relation between psychopathology of parents and child development is not limited to the mother-child relationship [3, 4]. For instance, postnatal paternal depression was associated with a higher likelihood of a psychiatric diagnosis in children at the age of 7 [5]. Next to the evidence for a postnatal effect of parental psychopathology on child development, there are also several reports suggesting a direct relation between maternal stress during pregnancy, such as depression and anxiety, and child development [6]. Interestingly, father s' prenatal depression has also been associated with the child development such as excessive infant crying [7], child anxiety [8], and conduct problems [9]. Genetic effects, programming effects in utero and differentiation effects after birth may account for these prenatal and postnatal associations [10]. During pregnancy, the comparison of the effect of maternal risk factors on the likelihood of child internalizing problems with the effect of paternal risk factors has been used to investigate the causality of the underlying association [11]. If only a maternal prenatal relation is found, this may be the result of specific intra-uterine programming effects. A prenatal effect of paternal risk factors more likely reflects long lasting effects such as a genetic risk for psychopathology or residual confounding (i.e. unmeasured variables account for the association).

Like depression, parental hostility is also a significant threat to child development $[12,13]$. Hostile behaviour of mothers and fathers is related to less optimal interactions with their children [14]. Parent-child hostility gives rise to fear, anger and distress, and increases the likelihood of aggressive behaviour and anxiety of the child [14, 15]. The actual effect of parental hostility seems to depend mainly on emotional and cognitive processes within the child, and on family processes such as the level of involvement of the child in parental disputes [16].

By way of daily interaction within families, parental psychopathology usually also affects contextual factors. In families with a depressed parent, the interaction between spouses is often characterized by increased hostility and tension [17]. These families report poor family functioning more frequently than families with no depressed parents [18]. Therefore, children in these families are not only at an increased risk of emotional and behavioural problems, because they have a parent with psychological problems, but also due to an increased likelihood of exposure to marital conflict and poor family functioning.
Previous research mostly focused on the interrelation of parental depression, hostility, marital conflict and family functioning on child development, and mediators of these associations [16, 19-21]. In a recent review in this field, it was suggested that parental psychopathology and family functioning have reciprocal effects without a causal primacy of one of the two [21]. The debate remains to what extent these apparent risk factors independently contribute to child problem behaviour when analysed simultaneously. Insight into the independent contributions of parental depression, parental hostility and family functioning to the risk of child problem behaviour is important for the development of effective prevention and intervention strategies.

In the present study, we aimed to test the following hypotheses: (1) prenatal psychological symptoms of parents are a risk factor for child emotional and behavioural problems independent of postnatal parental symptoms, (2) parental depressive symptoms and parental symptoms of hostility each contribute to the risk of emotional and behavioural problems in children. Given the dyadic nature of family functioning, we also expected to find an additional effect of family functioning on the risk of child problems, and (3) any prenatal effect of maternal psychological symptoms exceeds the effect of paternal psychological symptoms during pregnancy, due to the direct physiologic effects via the mother on the intrauterine environment of the foetus.

We tested these hypotheses in 2,698 families participating in an ongoing population-based cohort. To explore the specificity of our findings, we also examined the effect of other parental psychological symptoms, such as psychoticism and anxiety, on child emotional and behavioural problems. Furthermore, we examined the effect of parental depressive symptoms, parental hostility, and family functioning on subtypes of emotional and behavioural problems; emotionally reactive behaviour, anxious/depressed behaviour, somatic complaints, withdrawn behaviour, attention problems and aggressive behaviour.

\section{Methods}

\section{Design}

This study was embedded in the Generation R Study, a population-based cohort from foetal life onwards in Rotterdam, the Netherlands. The Generation R Study has previously been described in detail [22]. All children were born between April 2002 and January 2006. The study has been approved by the Medical Ethics Committee of the Erasmus Medical Center, Rotterdam (numbers: prenatal, MEC 198.782/2001/31 and postnatal, MEC 217.595/2002/ 
202). Written informed consent was obtained from all adult participants.

Population of analysis

In the Generation $\mathrm{R}$ cohort, complete information on depressive symptoms, symptoms of hostility during pregnancy and family functioning was obtained from 3,425 mothers and fathers. Families without father participation were not included in this study. Of the 3,425 couples, 2,698 filled out the questionnaire about child behaviour. Hence in total, 2,698 couples and children (79\% of 3,425) were included in the analyses.

Prenatal and postnatal psychological symptoms of the parents

Psychological symptoms of the parents were assessed at 20 weeks of pregnancy and when the child was 3 years old with the Brief Symptom Inventory (BSI), a validated selfreport questionnaire with 53 items to be answered on a five-point scale, ranging from " $0=$ not at all" to " $4=$ extremely" [23, 24]. These 53 items are classified in eight subscales; Depression, Hostility, Anxiety, Phobic Anxiety, Paranoid Ideation, Psychoticism, Interpersonal Sensitivity and Obsessive-Compulsive. This study focused mainly on depression and hostility. The Depression scale consists of six items, e.g. "I am feeling suicidal" and "I have no interest in anything". The Hostility scale consists of five items, e.g. "I have an urge to hit, injure or cause pain to others" and "I often get involved in arguments". Higher scores on these scales represent an increased occurrence of depressive symptoms or symptoms of hostility.

\section{Prenatal family functioning}

Family functioning was assessed by the subscale General Functioning of the Family Assessment Device [25] at 20 weeks pregnancy. General Functioning is a validated overall self-report measure of health and pathology of a family and consists of 12 items. Half of the items describe healthy functioning, e.g. "In times of crisis, we can turn to each other for support". The other half describes unhealthy items, e.g. "There are a lot of unpleasant and painful feelings in our family." Parents were asked to rate how well each item described their family by selecting from four different responses: strongly agree, agree, disagree or strongly disagree. The scores per item were summed and divided by 12 yielding a total score from 1 to 4 . A higher total score translates into less well-functioning families or poor family functioning.

\section{Child behaviour}

The Child Behavior Checklist/11/2-5 (CBCL/11/2-5) was used to obtain standardized parent reports of children's problem behaviour at the age of 3 years. This behavioural questionnaire contains 99 items, which are scored on a three-point scale; $0=$ not true, $1=$ somewhat true or sometimes true and $2=$ very or often true, based on the two preceding months. The Total Problems score is obtained by summing the scores of all 99 items. The Internalizing scale score is a sum score of the items $(N=36)$ in four syndrome scales: Emotionally Reactive, Anxious/Depressed, Somatic Complaints, and Withdrawn. The Externalizing scale score is a sum score of the items $(N=24)$ in the Attention Problems and Aggressive Behavior syndrome scales. The psychometric properties of the CBCL are well established [26]. In this study, we used the broadband scale Internalizing scale, the Externalizing scale and the syndrome scales (emotionally reactive, anxious/depressed, somatic complaints, withdrawn, attention problems, and aggression). The data could not be normalized and were analyzed as dichotomized variables. To obtain a score on emotional and behavioural problems based on the report of both parents, the scores on Internalizing and Externalizing of mother and father were standardized (Z-scores) and averaged. If only the score of one parent was available, this score was used (12\%). Dutch norm scores have not been published. As in previous analyses, we defined a non-optimal score as the highest $20 \%$ of Internalizing and Externalizing item scores [27]. Likewise, we calculated non-optimal scores of the syndrome scales.

\section{Other measurements}

Information on infant birth weight and gender was obtained from midwife and hospital registries. Gestational age was established by foetal ultrasound examinations within the Generation R Study. Information on parental age at child birth, parental educational level, maternal smoking and maternal alcohol use during pregnancy, birth order, age of the infant, and ethnicity of the infant was obtained by questionnaire. The highest completed education (primary school, secondary school and higher education) determined the educational level of the parents. Ethnicity of the infant was classified into two categories based on the parental country of birth. If both parents were non-Dutch, mother's ethnicity determined the ethnicity of the child. The group of children classified as Western includes Dutch, American Western (non-Hispanic Whites), Asian Western (Japan), European and Australian children. The Non-Western group comprised children with a Turkish, Moroccan, Surinamese, Cape Verdean, Dutch Antillean, African, American 
non-Western (Afro-Americans, Hispanics) and Asian nonWestern (Asia except Japan) ethnicity [28]. Maternal smoking and maternal alcohol use were assessed at three time-points during pregnancy and categorized into "yes, during pregnancy" and "never during pregnancy". The inclusion of these potential confounders was determined a priori and based on the existing knowledge about the association between parental psychopathology and child behaviour [6].

\section{Statistical analysis}

In a non-response analysis, differences in baseline characteristics of responders $(n=2,698)$ and non-responders $(n=727)$ on the assessment of child behaviour were compared with the Chi-square statistic for categorical variables, the independent $t$ test for normally distributed continuous variables and the Mann-Whitney $U$ test for non-normally distributed continuous variables. Likewise, we compared baseline characteristics between children with low scores on emotional and behavioural problems and children with high scores on emotional and behavioural problems. The correlation between the determinants was analyzed using the Spearman's correlation coefficient for non-parametric variables $\left(\rho_{\mathrm{sp}}\right)$. The continuous measures of parental depressive symptoms, family functioning and symptoms of hostility were expressed per standard deviation to facilitate comparisons of effect sizes.

First, we examined the direct effect of prenatal depressive symptoms, prenatal hostility symptoms, prenatal family functioning, postnatal depressive symptoms and postnatal hostility symptoms of the parents on child internalizing problems and child externalizing problems. These multivariate linear regression analyses were adjusted for covariates, but not for the other determinants. To test the specificity of these associations for depressive symptoms and hostility, we additionally examined the association of other prenatal maternal BSI subscales (Phobic Anxiety, Psychoticism, Paranoid Ideation, Obsessive-Compulsive, Interpersonal Sensitivity, Somatization and Anxiety) with child internalizing and externalizing problems.

Second, we examined the independent contribution of parental psychological problems and family functioning to the development of child internalizing and externalizing problems using multivariate linear regression analyses in five successive models. The first three models included the prenatal determinants, whereas the postnatal determinants were added in model 4 and model 5 . To test for significant difference between the odds ratios, we produced $84 \%$ confidence intervals $(84 \% \mathrm{CI})$ around the odds ratios and examined the overlap. As reported by Julious [29], the level of statistical significance between the two groups would be $5 \%$ or lower if the $84 \%$ confidence intervals around the odds ratios do not overlap. Third, we examined the association of parental psychological symptoms and family functioning with subtypes of internalizing and externalizing problems (model 5).

All analyses were controlled for child gender, birth weight, birth order, child ethnicity, child age, maternal smoking and drinking behaviour during pregnancy, parental age, as well as for parental education. Missing data were imputed using multiple imputation procedures. Test statistics and regression coefficients were averaged across five imputed data sets [30]. The level of significance for all analyses was set at $\alpha=0.05$. All statistical analyses were carried out using PASW Statistics, version 17.0 for Windows [30].

Non-response analysis

Mothers who did not complete the CBCL/1 $1 / 2-5$ were on average younger at child birth (29.2 vs. 31.6 years, $t=12.27, \mathrm{p}<0.001)$, were less likely high educated (20.3 vs. $\left.37.5 \%, \chi^{2}=76.17(1 \mathrm{df}), p<0.001\right)$, and more likely to smoke during pregnancy $\left(26.2\right.$ vs. $18.5 \%, \chi^{2}=21.06$ ( $1 \mathrm{df}), p<0.001$ than responding mothers. Likewise, fathers who did not complete the CBCL/1 $1 / 2-5$ were on average younger at child birth ( 32.2 vs. 33.9 years, $t=6.598, p<0.001)$, and were less high educated $(26.5$ vs. $\left.40.1 \%, \chi^{2}=45.67(1 \mathrm{df}), p<0.001\right)$ than responding fathers. Children of non-responding mothers had on average a lower birth weight $(3,363$ vs. $3,480 \mathrm{~g}, t=5.05$, $p<0.001)$ and the origin of these children was less likely Dutch or Western $\left(63.6\right.$ vs. $84.8 \%, \chi^{2}=163.16(1 \mathrm{df})$, $p<0.001)$ compared with children of mothers who did complete the CBCL/1 $1 \frac{1}{2}-5$.

\section{Results}

Table 1 presents the subject characteristics in the group of children with low internalizing problems compared with the subject characteristics in the group of children with high internalizing problems. Mothers of children with high internalizing problems were on average younger at child birth (mean 30.8 vs. 31.8 years, $t=5.39, p<0.001$ ) and were less likely highly educated (33.8 vs. $39.2 \%$, $\left.\chi^{2}=5.06(1 \mathrm{df}), p=0.021\right)$ than mothers of children with low internalizing problems. Paternal characteristics showed a similar distribution over the groups compared with maternal characteristics. The children with high internalizing problems were more likely firstborns ( 72.8 vs. $60.5 \%$, $\left.\chi^{2}=27.88(1 \mathrm{df}), p<0.001\right)$, had on average a lower birth weight $(3,422$ vs. $3,495 \mathrm{~g}, t=2.27, p=0.006)$ and were less often of Western origin (78.3 vs. $86.9 \%, \chi^{2}=19.71$ (1 df), $p<0.001$ ) compared with children with low 
Table 1 Subject characteristics $(n=2,698)$

\begin{tabular}{|c|c|c|c|c|}
\hline & \multicolumn{2}{|c|}{ Child internalizing problems reported by both parents } & \multirow[t]{2}{*}{ Test statistic } & \multirow[t]{2}{*}{$p$ value $^{\mathrm{b}}$} \\
\hline & $\begin{array}{l}\text { Low internalizing } \\
\text { problems }(n=2,162)^{\mathrm{a}}\end{array}$ & $\begin{array}{l}\text { High internalizing } \\
\text { problems }(n=536)^{\mathrm{a}}\end{array}$ & & \\
\hline \multicolumn{5}{|l|}{ Mother } \\
\hline Age at child birth (years) & $31.8(4.0)$ & $30.8(4.1)$ & 5.39 & $<0.001$ \\
\hline \multicolumn{5}{|l|}{ Education $(\%)$} \\
\hline Higher education & 39.2 & 33.8 & 5.06 & 0.021 \\
\hline \multicolumn{5}{|l|}{ Smoking during pregnancy $(\%)$} \\
\hline Never & 82.0 & 79.9 & 1.27 & 0.260 \\
\hline \multicolumn{5}{|l|}{ Alcohol during pregnancy $(\%)$} \\
\hline Never & 30.8 & 37.1 & 8.00 & 0.005 \\
\hline \multicolumn{5}{|l|}{ Birth order $(\%)$} \\
\hline First child & 60.5 & 72.8 & 27.88 & $<0.001$ \\
\hline \multicolumn{5}{|l|}{ Father } \\
\hline Age at child birth (years) & $34.0(5.0)$ & $33.3(4.8)$ & 2.88 & 0.004 \\
\hline \multicolumn{5}{|l|}{ Education (\%) } \\
\hline Higher education & 41.6 & 36.2 & 5.17 & 0.023 \\
\hline \multicolumn{5}{|l|}{ Child } \\
\hline Gender (\%boys) & 50.1 & 48.3 & 0.57 & 0.451 \\
\hline Gestational age at birth (weeks) & $40.1(27.6-43.4)^{\mathrm{c}}$ & $40.1(29.6-42.9)^{\mathrm{c}}$ & 1.44 & 0.212 \\
\hline Birth weight (g) & $3495(553)$ & $3422(583)$ & 2.27 & 0.006 \\
\hline \multicolumn{5}{|l|}{ Ethnicity (\%) } \\
\hline Dutch/other Western & 86.9 & 78.3 & 19.71 & $<0.001$ \\
\hline
\end{tabular}

Low internalizing problems were defined as scores below the 80th percentile on the Internalizing scale of the Child Behavior Checklist and High internalizing problems as scores at the 80th percentile and higher on the Internalizing scale of the Child Behavior Checklist

${ }^{a}$ Mean (standard deviation) unless otherwise indicated

b With the chi-square statistic for categorical variables (parental education, smoking during pregnancy, alcohol during pregnancy, gender, child ethnicity), the independent $t$ test for normally distributed continuous variables (parental age, birth weight) and the Mann-Whitney $U$ test for nonnormally distributed continuous variables (gestational age)

c Median (100\% range)

internalizing problem scores. The comparison of children with low externalizing problems and high externalizing problems showed a similar distribution of characteristics, except for maternal smoking during pregnancy $(\%$ never during pregnancy 82.9 vs. $76.0, \quad \chi^{2}=13.96(1 \mathrm{df}$, $p<0.001)$ and gender (\% boys 47.1 vs. $60.3, \chi^{2}=29.74$ (1 df, $p<0.001)$ (data not shown).

Prenatal depressive symptoms, prenatal hostility, prenatal family functioning, postnatal depressive symptoms and postnatal hostility of the parents were significantly correlated ( $p$ value $<0.001$ ), and the highest correlation was found between depressive symptoms and symptoms of hostility (e.g. $\rho_{\mathrm{sp}}$ prenatal maternal depressive symptomsprenatal maternal hostility 0.50 , p value $<0.001$ ) (Appendix Table 1). Co-linearity among BSI sub-scales was indicated by correlations of $0.31-0.64$. For instance, we found a correlation of 0.52 for BSI depression and BSI anxiety, for BSI depression with BSI phobic anxiety a correlation of 0.37 , for BSI hostility with BSI anxiety a correlation of 0.48 and a correlation for hostility with phobic anxiety of 0.31 .

As presented in Table 2, parental prenatal depressive symptoms, parental prenatal symptoms of hostility, parental prenatal family functioning, parental postnatal depressive symptom and parental postnatal symptoms of hostility were all significantly associated with an increased likelihood of child internalizing problems (OR range 1.14-1.54, $p$ values $<0.01$ ) and child externalizing problems (OR range $1.06-1.38, p$ values $<0.01$ ). The other prenatal BSI subscale scores of the mother also predicted child internalizing problems (OR of Phobic Anxiety 1.18, OR of Paranoid Ideation 1.24, OR of Psychoticism 1.26, OR of Interpersonal Sensitivity 1.30 , OR of Anxiety 1.34, OR of ObsessiveCompulsive 1.37 , all $p$ values $<0.001$ ) and child externalizing problems (OR of Phobic Anxiety 1.15, OR of Paranoid Ideation 1.23, OR of Psychoticism 1.21, OR of Interpersonal Sensitivity 1.27 , OR of Anxiety 1.22 , OR of ObsessiveCompulsive 1.42 , all $p$ values $<0.01$. 
Table 2 The associations of parental symptoms of psychopathology and prenatal family functioning with child emotional and behavioural problems as reported by both parents

\begin{tabular}{|c|c|c|c|c|c|c|}
\hline & \multicolumn{3}{|c|}{$\begin{array}{l}\text { Child internalizing problems at } 3 \text { years reported by both parents } \\
\text { (per SD) }\end{array}$} & \multicolumn{3}{|c|}{$\begin{array}{l}\text { Child externalizing problems at } 3 \text { years reported by both parents } \\
\text { (per SD) }\end{array}$} \\
\hline & $\mathrm{OR}^{\mathrm{a}}$ & $95 \% \mathrm{CI}$ & $p$ value & $\mathrm{OR}^{\mathrm{a}}$ & $95 \% \mathrm{CI}$ & $p$ value \\
\hline \multicolumn{7}{|c|}{ Prenatal depressive symptoms per SD $(n=2,698)$} \\
\hline Mother & 1.21 & $1.11 ; 1.32$ & $<0.001$ & 1.23 & $1.13 ; 1.34$ & $<0.001$ \\
\hline Father & 1.18 & $1.08 ; 1.29$ & $<0.001$ & 1.16 & $1.060 ; 1.26$ & 0.001 \\
\hline \multicolumn{7}{|c|}{ Prenatal hostility symptoms per SD $(n=2,698)$} \\
\hline Mother & 1.27 & $1.16 ; 1.39$ & $<0.001$ & 1.29 & $1.18 ; 1.41$ & $<0.001$ \\
\hline Father & 1.23 & $1.13 ; 1.34$ & $<0.001$ & 1.23 & $1.13 ; 1.34$ & $<0.001$ \\
\hline \multicolumn{7}{|c|}{ Prenatal family functioning per $\operatorname{SD}(n=2,698)$} \\
\hline Mother & 1.14 & $1.04 ; 1.25$ & $<0.001$ & 1.24 & $1.13 ; 1.36$ & $<0.001$ \\
\hline Father & 1.18 & $1.07 ; 1.30$ & 0.001 & 1.19 & $1.08 ; 1.31$ & 0.001 \\
\hline \multicolumn{7}{|c|}{ Postnatal depressive symptoms per SD (3 years after birth) $(n=2,692)$} \\
\hline Mother & 1.37 & $1.25 ; 1.50$ & $<0.001$ & 1.32 & $1.21 ; 1.44$ & $<0.001$ \\
\hline Father & 1.24 & $1.14 ; 1.35$ & $<0.001$ & 1.26 & $1.16 ; 1.37$ & $<0.001$ \\
\hline \multicolumn{7}{|c|}{ Postnatal hostility symptoms per SD (3 years after birth) $(n=2,696)$} \\
\hline Mother & 1.54 & $1.40 ; 1.69$ & $<0.001$ & 1.51 & $1.38 ; 1.66$ & $<0.001$ \\
\hline Father & 1.42 & $1.30 ; 1.55$ & $<0.001$ & 1.44 & $1.32 ; 1.57$ & $<0.001$ \\
\hline
\end{tabular}

Reference group $=$ children with Internalizing Problem scores/Externalizing Problem scores below the 80th percentile on the Child Behavior Checklist

All analyses were adjusted for child gender, birth weight, birth order, ethnicity, child age at questionnaire, maternal smoking and alcohol use during pregnancy, parental age and parental educational level. Small differences in numbers due to the exclusion of outliers in postnatal psychological symptoms

$O R$ odds ratio, $C I$ confidence interval

${ }^{a}$ OR's represent the increased risk of internalizing and externalizing problem scores per standard deviation (SD) increase of the determinants

In Table 3, we present the association of parental psychological symptoms and family functioning with child internalizing problems in five successive models. The prenatal analyses showed that prenatal depressive symptoms of mothers and fathers each predicted internalizing problems (model 1). However, these associations were no longer significant when prenatal parental hostility was added to the regression analysis (model 2). In model 3, a higher score on prenatal family functioning experienced by the mother was associated with an increased risk of child internalizing problems (OR 1.25, 95\% CI 1.12; 1.39, $p$ value $<0.001)$. Prenatal family functioning experienced by the father was not significantly associated with child internalizing problems. In model 4 and 5, postnatal determinants were added to the analyses. As shown in these models, we found that the initially significant associations of postnatal depressive symptoms of mother and father with an increased risk of internalizing problems were no longer significant after adding postnatal parental symptoms of hostility. The final model (model 5) showed that poor family functioning experienced by the mother during pregnancy (OR $1.23,95 \%$ CI $1.10 ; 1.37, p$ value $<0.001$ ), postnatal symptoms of hostility of mother (OR $1.35,95 \%$ CI $1.20 ; 1.52, p$ value $<0.001$ ), and postnatal symptoms of hostility of father (OR 1.30, 95\% CI 1.17; 1.46, $p$ value $<0.001)$ were all independently associated with an increased risk of child internalizing problems. The same pattern was found for the associations between the determinants and child externalizing problems (Table 4); postnatal symptoms of hostility of the mother (OR 1.34, 95\% CI $1.20 ; 1.50, p$ value $<0.001$ ) and of the father (OR 1.33, $95 \%$ CI $1.19 ; 1.48, p$ value $<0.001$ ) independently contributed to the likelihood of child externalizing problems. Also, the effects of the determinants on the risk of child internalizing problems and child externalizing problems were not significantly different, since the $84 \%$ confidence intervals of the ORs overlap (data not shown).

The analyses of parental psychopathology symptoms and prenatal family functioning with subtypes of internalizing problems and externalizing problems showed that postnatal symptoms of hostility of mothers and fathers each significantly increased the likelihood of all six subtypes of child emotional and behavioural problems at the age of 3 years (OR range 1.15-1.37) (see appendix Tables 2 and Table 3). Next to these significant observations, prenatal depressive symptoms of the mother were primarily related to anxious/depressed behaviour and emotionally reactive behaviour. Prenatal symptoms of hostility of the mother 
Table 3 The association of family functioning and parental psychopathology with child internalizing problems as reported by both parents in mutually adjusted successive models

\begin{tabular}{|c|c|c|c|c|c|c|c|c|c|c|c|c|c|c|}
\hline \multirow{3}{*}{$\begin{array}{l}\text { Successive } \\
\text { models }\end{array}$} & \multicolumn{14}{|c|}{ Child internalizing problems at 3 years reported by both parents (per SD) } \\
\hline & \multicolumn{2}{|c|}{ Model $1(n=2,698)$} & \multicolumn{3}{|c|}{ Model $2(n=2,698)$} & \multicolumn{3}{|c|}{ Model $3(n=2,698)$} & \multicolumn{3}{|c|}{ Model $4(n=2,687)$} & \multicolumn{3}{|c|}{ Model $5(n=2,685)^{\mathrm{a}}$} \\
\hline & $\mathrm{OR}^{\mathrm{b}} \quad 95 \% \mathrm{CI}$ & $p$ & $\mathrm{OR}^{\mathrm{b}}$ & $95 \% \mathrm{CI}$ & $p$ & $\mathrm{OR}^{\mathrm{b}}$ & $95 \% \mathrm{CI}$ & $p$ & $\mathrm{OR}^{\mathrm{b}}$ & $95 \% \mathrm{CI}$ & $p$ & $\mathrm{OR}^{\mathrm{b}}$ & $95 \% \mathrm{CI}$ & $p$ \\
\hline \multicolumn{15}{|c|}{ Prenatal depressive symptoms per SD } \\
\hline Mother & $1.18 \quad 1.08 ; 1.29$ & $<0.001$ & 1.07 & $0.96 ; 1.19$ & 0.23 & 1.04 & $0.93 ; 1.16$ & 0.49 & 1.01 & $0.90 ; 1.13$ & 0.75 & 1.06 & $0.94 ; 1.19$ & 0.36 \\
\hline Father & $1.15 \quad 1.05 ; 1.26$ & 0.002 & 1.07 & $0.96 ; 1.19$ & 0.22 & 1.05 & $0.94 ; 1.17$ & 0.33 & 1.01 & $0.92 ; 1.13$ & 0.74 & 1.04 & $0.93 ; 1.16$ & 0.52 \\
\hline \multicolumn{15}{|c|}{ Prenatal hostility symptoms per SD } \\
\hline Mother & & & 1.18 & $1.05 ; 1.32$ & 0.004 & 1.15 & $1.02 ; 1.29$ & 0.02 & 1.12 & $1.00 ; 1.26$ & 0.07 & 1.04 & $0.92 ; 1.17$ & 0.52 \\
\hline Father & & & 1.15 & $1.04 ; 1.28$ & 0.008 & 1.14 & $1.02 ; 1.27$ & 0.02 & 1.13 & $1.01 ; 1.26$ & 0.03 & 1.06 & $0.95 ; 1.19$ & 0.31 \\
\hline \multicolumn{15}{|c|}{ Prenatal family functioning per SD } \\
\hline Mother & & & & & & 1.28 & $1.15 ; 1.42$ & $<0.001$ & 1.25 & $1.12 ; 1.39$ & $<0.001$ & 1.23 & $1.10 ; 1.37$ & $<0.001$ \\
\hline Father & & & & & & 0.99 & $0.89 ; 1.11$ & 0.92 & 0.97 & $0.87 ; 1.08$ & 0.65 & 0.96 & $0.83 ; 1.05$ & 0.51 \\
\hline \multicolumn{15}{|c|}{ Postnatal depressive symptoms per SD (3 years after birth) } \\
\hline Mother & & & & & & & & & 1.24 & $1.13 ; 1.36$ & $<0.001$ & 1.07 & $0.96 ; 1.20$ & 0.28 \\
\hline Father & & & & & & & & & 1.11 & $1.01 ; 1.22$ & 0.02 & 0.99 & $0.88 ; 1.10$ & 0.82 \\
\hline \multicolumn{15}{|c|}{ Postnatal hostility symptoms per SD (3 years after birth) } \\
\hline Mother & & & & & & & & & & & & 1.35 & $1.20 ; 1.52$ & $<0.001$ \\
\hline Father & & & & & & & & & & & & 1.30 & $1.17 ; 1.46$ & $<0.001$ \\
\hline
\end{tabular}

Reference group = children with Internalizing Problem scores below the 80th percentile on the Child Behavior Checklist

All analyses were adjusted for child gender, birth weight, birth order, ethnicity, child age at questionnaire, maternal smoking and alcohol use during pregnancy, parental age and parental educational level. Only mutually adjusted results are reported. Small differences in numbers due to the exclusion of outliers in postnatal psychological symptoms

$O R$ odds ratio, $C I$ confidence interval, $p: p$ value

${ }^{a}$ Model 1: prenatal depressive symptoms score of mother and father, model 2: model $1+$ prenatal symptoms of hostility score of mother and father, model 3 : model $2+$ prenatal family functioning reported by mother and father, model 4: model $3+$ postnatal depressive symptoms score of mother and father, model 5: model $4+$ postnatal symptoms of hostility score of mother and father. All reported per standard deviation to facilitate the comparison of these measurements

b OR's represent the increased risk of internalizing problems per standard deviation (SD) increase of the determinants

predicted child aggressive behaviour, whereas prenatal symptoms of hostility of the father were significantly associated with emotionally reactive behaviour of the child. Furthermore, prenatal family functioning reported by the mother was associated with anxious/depressed behaviour, emotionally reactive behaviour and somatic complaints, whereas prenatal family functioning reported by the father was related to somatic complaints of children (see appendix Tables 2 and 3).

\section{Discussion}

This study examined the risk of prenatal and postnatal parental depressive symptoms, prenatal and postnatal parental hostility and prenatal family functioning for emotional and behavioural problems in young children. We first evaluate prenatal and postnatal effects of parental psychological symptoms. The associations of parental prenatal depressive symptoms and prenatal hostility of the parents with child internalizing and externalizing problems were not independent of the effect of postnatal parental hostility with the outcome. This may suggest that parentchild interaction is essential to determine the impact of parental psychopathology on children, or that it is easier to detect an immediate effect than a distant effect of a stressor on child development. However, these findings make it also more likely that the effects of postnatal parental symptoms of hostility on child behaviour are causal, because some form of hostility in the parent was already present before birth of the child. Child emotional and behavioural problems can be a source of postnatal parental psychological problems [12, 13], but this reasoning cannot account for parental hostility prior to birth of the offspring, thus reverse causality is less likely.

Our second hypothesis posited that parental depressive symptoms, parental hostility and family functioning would have independent effects on child development. Although initially significant, the effects of parental depressive symptoms on child internalizing problems and child 
Table 4 The association of family functioning and parental psychopathology with child externalizing problems as reported by both parents in mutually adjusted successive models

\begin{tabular}{|c|c|c|c|c|c|c|c|c|c|c|c|c|c|c|}
\hline \multirow{3}{*}{$\begin{array}{l}\text { Successive } \\
\text { models }\end{array}$} & \multicolumn{14}{|c|}{ Child externalizing problems at 3 years reported by both parents (per SD) } \\
\hline & \multicolumn{2}{|c|}{ Model $1(n=2,698)$} & \multicolumn{3}{|c|}{ Model $2(n=2,698)$} & \multicolumn{3}{|c|}{ Model $3(n=2,698)$} & \multicolumn{3}{|c|}{ Model $4(n=2,687)$} & \multicolumn{3}{|c|}{ Model $5(n=2,685)^{\mathrm{a}}$} \\
\hline & $\mathrm{OR}^{\mathrm{b}} 95 \% \mathrm{CI}$ & & $\mathrm{OR}^{\mathrm{b}}$ & $95 \% \mathrm{CI}$ & $p$ & $\mathrm{OR}^{\mathrm{b}}$ & $95 \% \mathrm{CI}$ & $p$ & $\mathrm{OR}^{\mathrm{b}}$ & $95 \% \mathrm{CI}$ & $p$ & $\mathrm{OR}^{\mathrm{b}}$ & $95 \% \mathrm{CI}$ & $p$ \\
\hline \multicolumn{15}{|c|}{ Prenatal depressive symptoms per SD } \\
\hline Mother & $1.191 .09 ; 1.30$ & $<0.001$ & 1.09 & $0.98 ; .1 .22$ & 0.14 & 1.06 & $0.95 ; 1.18$ & 0.29 & 1.03 & $0.92 ; 1.16$ & 0.59 & 1.07 & $0.95 ; 1.21$ & 0.25 \\
\hline Father & $1.121 .02 ; 1.23$ & 0.009 & 1.04 & $0.94 ; 1.16$ & 0.48 & 1.03 & $0.96 ; 1.15$ & 0.60 & 1.01 & $0.91 ; 1.13$ & 0.88 & 1.03 & $0.92 ; 1.15$ & 0.63 \\
\hline \multicolumn{15}{|c|}{ Prenatal hostility symptoms per SD } \\
\hline Mother & & & 1.19 & $1.06 ; 1.33$ & 0.003 & 1.17 & $1.04 ; 1.31$ & 0.006 & 1.15 & $1.02 ; 1.29$ & 0.02 & 1.07 & $0.95 ; 1.21$ & 0.25 \\
\hline Father & & & 1.16 & $1.04 ; 1.29$ & 0.005 & 1.15 & $1.03 ; 1.28$ & 0.013 & 1.12 & $1.00 ; 1.25$ & 0.04 & 1.05 & $0.94 ; 1.18$ & 0.37 \\
\hline \multicolumn{15}{|c|}{ Prenatal family functioning per SD } \\
\hline Mother & & & & & & 1.15 & $1.04 ; 1.28$ & 0.010 & 1.11 & $1.02 ; 1.29$ & 0.05 & 1.10 & $0.99 ; 1.23$ & 0.08 \\
\hline Father & & & & & & 1.04 & $0.93 ; 1.16$ & 0.494 & 1.01 & $0.90 ; 1.13$ & 0.79 & 1.00 & $0.89 ; 1.12$ & 0.97 \\
\hline \multicolumn{15}{|c|}{ Postnatal depressive symptoms per SD (3 years after birth) } \\
\hline Mother & & & & & & & & & 1.19 & $1.08 ; 1.31$ & $<0.001$ & 1.02 & $0.91 ; 1.14$ & 0.68 \\
\hline Father & & & & & & & & & 1.15 & $1.05 ; 1.26$ & 0.004 & 1.00 & $0.90 ; 1.12$ & 0.93 \\
\hline \multicolumn{15}{|c|}{ Postnatal hostility symptoms per SD (3 years after birth) } \\
\hline Mother & & & & & & & & & & & & 1.34 & $1.20 ; 1.50$ & $<0.001$ \\
\hline Father & & & & & & & & & & & & 1.33 & $1.19 ; 1.48$ & $<0.001$ \\
\hline
\end{tabular}

Reference group $=$ children with Externalizing Problem scores below the 80th percentile on the Child Behavior Checklist

All analyses were adjusted for child gender, birth weight, birth order, ethnicity, child age at questionnaire, maternal smoking and alcohol use during pregnancy, parental age and parental educational level. Only mutually adjusted results are reported. Small differences in numbers due to the exclusion of outliers in postnatal psychological symptoms

$O R$ odds ratio, $C I$ confidence interval, $p p$ value

${ }^{a}$ Model 1: prenatal depressive symptoms score of mother and father, model 2: model $1+$ prenatal symptoms of hostility score of mother and father, model 3: model $2+$ prenatal family functioning reported by mother and father, model 4: model $3+$ postnatal depressive symptoms score of mother and father, model 5: model $4+$ postnatal symptoms of hostility score of mother and father. All reported per standard deviation to facilitate the comparison of these measurements

${ }^{b}$ OR's represent the increased risk of externalizing problems per standard deviation (SD) increase of the determinants

externalizing problems were accounted for by postnatal parental hostility. Hence, when analysed simultaneously with parental depressive symptoms, the impact of parental hostility after birth on child development seemed larger. However, we cannot conclude that depressive symptoms of the parents do not affect these families. It has been reported that persons with a depression show more nonverbal expressions of hostility in their interactions than nondepressed persons [31]. In our study, this comorbidity was reflected by moderately strong correlations between depressive symptoms and symptoms of hostility. Also, in the subtype analyses, prenatal maternal depressive symptoms significantly predicted child anxious/depressed behaviour and emotionally reactive behaviour, independent of parental hostility.

We also report that poor family functioning during pregnancy experienced by the mother increases the risk of child internalizing problems, independently of the increased risk associated with parental postnatal hostility. The association between family functioning and child behavioural problems has been previously documented $[15,32]$. In this field of research, many studies, however, focused on the combined effect of family functioning and parental psychopathology on child development [14, 16, 19, 20, 32]. Our findings seem to underscore the importance of family life to child development, next to the effect of parental symptoms of psychopathology. Interestingly, this association may be specific for child internalizing problems, as we did not find an independent effect of prenatal family functioning on child externalizing problems.

To test the third hypothesis, we focused on the effects of maternal risk factors and the effects of paternal risk factors on child emotional and behavioural problems. Remarkably, the postnatal effect of father's hostility was similar to the effect estimate of mother's hostility on the likelihood of child internalizing and externalizing problems. These findings underscore the importance of father's behaviour on child development, and point to the fact that even subtle hostility by father affects their children. In contrast, father's experience of family functioning was not significantly associated with child internalizing problems. Fathers may have different views on family functioning compared 
to mothers. In our study, however, mothers and fathers report quite similar on family functioning in terms of total range of scores and mean scores. As both parents' reports of family functioning were included in one regression model (Table 3), it may also be that the effect of father's experience of family functioning is captured in mother's experience of family functioning.

Two methodological considerations need to be discussed. First, we want to address the specificity of our findings. The associations of parental depressive symptoms and hostility with child internalizing and externalizing problems were not specific; other BSI subscales also predicted child problems. This indicates strongly that these scales partly represent general psychopathology. We also found similar effects of postnatal parental hostility on child internalizing and child externalizing problems. If anything, family functioning reported by the mother was associated with a somewhat higher risk of internalizing problems compared with externalizing problems. This absence of effect specificity is not surprising, given the high level of comorbidity among psychiatric disorders in children [33]. Recently, Kessler and colleagues [34] reported, even in adults, significant associations of "virtually all temporally primary lifetime disorders predicting subsequent onset of other disorders" in a study of lifetime comorbidity.

Secondly, the question of a multiple testing problem must be discussed. We studied the effect of several related risk factors on child emotional and behavioural problems. However, the tests do not constitute independent hypotheses. Hence we did not adjust for multiple testing. If we, however, would apply a Bonferroni correction, the corrected alpha for chance is $0.05 / 10=0.005$ which would not change the interpretation of our findings. The $p$ values of the significant associations of postnatal parental hostility and child problems presented in Tables 3 and 4 are smaller than 0.001. Moreover, appendix Tables 2 and 3 present additional analyses of syndrome scales that further explore the results obtained with the broadband scale Internalizing and Externalizing. Hence, the aim here was not to test more hypotheses, but to explain the results observed.

The present study has several strengths. First, both mother and father participated in this study, and thus information about depressive symptoms, hostility and family functioning of both parents was available. This enabled us to study the maternal and paternal effects on child development separately. Second, child emotional and behavioural problems were assessed separately by mother and father. Using multiple informants increased the reliability of our findings, and reduced the risk of reporter bias. Since assessment of behaviour will always be subjective, reporter bias may occur if, for instance, a depression of the mother influences her view on her child's behaviour [35]. Third, our study was embedded in a large birth cohort, which made it possible to adjust for numerous confounders. Besides these strengths, this study has also limitations. First, our response analyses showed that selection occurred toward well functioning families with a higher social economic status (SES). As partner participation is higher in families with higher SES, our study was prone to represent more well-functioning families [36]. Second, observational measurements in this large cohort were not feasible. Therefore, we relied on report of mothers and fathers on psychological symptoms, family functioning and child behaviour. Yet, we used validated questionnaires with good reliability and validity. Third, as this study was performed in a fairly healthy population we should be careful generalizing our findings to clinical populations.

In conclusion, we found that family functioning experienced by the mother and postnatal hostile behaviour of parents independently contributed to the risk of internalizing problems in 3-year-old children. Parental postnatal hostile behaviour was also related to child externalizing problems. Interestingly, parental hostility accounted for the effect of parental depressive symptoms on child internalizing and externalizing problems. These findings suggest that prevention and intervention strategies should focus on the psychological symptoms of both mothers and fathers, in particular on hostile behaviour, in families with young children.

Acknowledgments The Generation R Study is conducted by the Erasmus Medical Centre in close collaboration with the Erasmus University Rotterdam, School of Law and Faculty of Social Sciences, the Municipal Health Service Rotterdam area, Rotterdam, the Rotterdam Homecare Foundation, Rotterdam, and the Stichting Trombosedienst \& Artsenlaboratorium Rijnmond (STAR), Rotterdam. We gratefully acknowledge all participants and the contribution of general practitioners, hospitals, midwives and pharmacies in Rotterdam. The first phase of the Generation R Study is made possible by financial support from: Erasmus Med-ical Centre, Rotterdam, Erasmus University Rotter-dam and the Netherlands Organization for Health Research and Development (ZonMw). The present study was supported by a grant from the Sophia Foundation for Scientific Research (SKZ Foundation) (grant no.491) and ZonMw (grant no.10.000.1003).

Conflict of interest The authors declare no conflict of interest. Prof. Dr. F.C. Verhulst is a contributing author of the Achenbach System of Emperically Based Assessments, from which he receives remuneration.

Open Access This article is distributed under the terms of the Creative Commons Attribution Noncommercial License which permits any noncommercial use, distribution, and reproduction in any medium, provided the original author(s) and source are credited.

\section{References}

1. Gelfand D, Teti D (1990) The effects of maternal depression on children. Clin Psychol Rev 10:329-353 
2. Goodman SH (2007) Depression in mothers. Annu Rev Clin Psychol 3:107-135

3. Phares V, Compas B (1992) The role of fathers in child and adolescent psychopathology: make room for daddy. Psychol Bull 111(3):387-412

4. Ramchandani P, Psychogiou L (2009) Paternal psychiatric disorders and children's psychosocial development. Lancet 374(9690):646-653

5. Ramchandani PG, Stein A, O'Connor TG, Heron J, Murray L, Evans J (2008) Depression in men in the postnatal period and later child psychopathology: a population cohort study. J Am Acad Child Adolesc Psychiatry 47(4):390-398

6. Van den Bergh BR, Mulder EJ, Mennes M, Glover V (2005) Antenatal maternal anxiety and stress and the neurobehavioural development of the fetus and child: links and possible mechanisms. A review. Neurosci Biobehav Rev 29(2):237-258

7. van den Berg MP, van der Ende J, Crijnen AA, Jaddoe VW, Moll HA, Mackenbach JP, Hofman A, Hengeveld MW, Tiemeier H, Verhulst FC (2009) Paternal depressive symptoms during pregnancy are related to excessive infant crying. Pediatrics 124(1): e96-e103

8. Colletti CJ, Forehand R, Garai E, Rakow A, McKee L, Fear JM, Compas BE (2009) Parent depression and child anxiety: an overview of the literature with clinical implications. Child Youth Care Forum 38(3):151-160

9. Ramchandani PG, O'Connor TG, Evans J, Heron J, Murray L, Stein A (2008) The effects of pre- and postnatal depression in fathers: a natural experiment comparing the effects of exposure to depression on offspring. J Child Psychol Psychiatry 49(10):10691078

10. Lupien SJ, McEwen BS, Gunnar MR, Heim C (2009) Effects of stress throughout the lifespan on the brain, behaviour and cognition. Nat Rev Neurosci 10(6):434-445

11. Brion MJ, Zeegers M, Jaddoe V, Verhulst F, Tiemeier H, Lawlor DA, Smith GD (2011) Intrauterine effects of maternal prepregnancy overweight on child cognition and behavior in 2 cohorts. Pediatrics 127(1):e202-e211

12. Gordis EB, Margolin G, John RS (2001) Parents' hostility in dyadic marital and triadic family settings and children's behavior problems. J Consult Clin Psychol 69(4):727-734

13. Richmond MK, Stocker CM (2008) Longitudinal associations between parents' hostility and siblings' externalizing behavior in the context of marital discord. J Fam Psychol 22(2):231-240

14. Low SM, Stocker C (2005) Family functioning and children's adjustment: Associations among parents' depressed mood, marital hostility, parent-child hostility, and children's adjustment. J Fam Psychol 19(3):394-403

15. Emery RE (1982) Interparental conflict and the children of discord and divorce. Psychol Bull 92(2):310-330

16. Fosco GM, Grych JH (2008) Emotional, cognitive, and family systems mediators of children's adjustment to interparental conflict. J Fam Psychol 22(6):843-854

17. Kahn J, Coyne J, Margolin G (1985) Depression and marital disagreement: the social construction of despair. J Soc Pers Relationsh 2(4):447-461

18. Hughes EK, Gullone E (2008) Internalizing symptoms and disorders in families of adolescents: a review of family systems literature. Clin Psychol Rev 28(1):92-117

19. Katz LF, Gottman JM (1996) Spillover effects of marital conflict: in search of parenting and coparenting mechanisms. New Dir Child Dev 74:57-76
20. Goodman SH, Gotlib IH (1999) Risk for psychopathology in the children of depressed mothers: a developmental model for understanding mechanisms of transmission. Psychol Rev 106(3): 458-490

21. Rehman US, Gollan J, Mortimer AR (2008) The marital context of depression: research, limitations, and new directions. Clin Psychol Rev 28(2):179-198

22. Jaddoe VW, van Duijn CM, van der Heijden AJ, Mackenbach JP, Moll HA, Steegers EA, Tiemeier H, Uitterlinden AG, Verhulst FC, Hofman A (2010) The generation r study: design and cohort update 2010. Eur J Epidemiol 25(11):823-841

23. de Beurs E (2004) Brief symptom inventory, handleiding. Leiden, The Netherlands

24. Derogatis LR (1993) Brief symptom inventory (bsi): Administration, scoring and procedures manual, 3rd edn. National Computer Systems Inc., Minneapolis

25. Byles J, Byrne C, Boyle MH, Offord DR (1988) Ontario-childhealth-study - reliability and validity of the general functioning subscale of the mcmaster family assessment device. Fam Process 27(1):97-104

26. Achenbach TM, Rescorla LM (2000) Manual for the aseba preschool form \& profiles. University of Vermont, Research Center for Children. Youth \& Families, Burlington

27. Cents RA, Tiemeier H, Luijk MP, Jaddoe VW, Hofman A, Verhulst FC, Lambregtse-van den Berg MP (2011) Grandparental anxiety and depression predict young children's internalizing and externalizing problems the generation $\mathrm{r}$ study. J Affect Disord 128(1-2):95-105

28. Statistics Netherlands (2004) Allochtonen in Nederland 2004 [foreigners in the Netherlands 2004]. Voorburg/Heerlen

29. Julious S (2004) Using confidence intervals around individual means to assess statistical significance between two means. Pharm Stat 3:217-222

30. SPSS (2009) PASW Statistics, Rel. 17.0.2. SPSS, Chicago

31. Troisi A, Moles A (1999) Gender differences in depression: an ethological study of nonverbal behavior during interviews. J Psychiatr Res 33(3):243-250

32. Grych JH, Fincham FD (1990) Marital conflict and children's adjustment: a cognitive-contextual framework. Psychol Bull 108(2):267-290

33. Angold A, Costello EJ, Erkanli A (1999) Comorbidity. J Child Psychol Psychiatry 40(1):57-87

34. Kessler RC, Ormel J, Petukhova M, McLaughlin KA, Green JG, Russo LJ, Stein DJ, Zaslavsky AM, Aguilar-Gaxiola S, Alonso J, Andrade L, Benjet C, de Girolamo G, de Graaf R, Demyttenaere K, Fayyad J, Haro JM, Hu CY, Karam A, Lee S, Lepine JP, Matchsinger H, Mihaescu-Pintia C, Posada-Villa J, Sagar R, Ustun TB (2011) Development of lifetime comorbidity in the world health organization world mental health surveys. Arch Gen Psychiatry 68(1):90-100

35. Fergusson DM, Lynskey MT, Horwood LJ (1993) The effect of maternal depression on maternal ratings of child behavior. J Abnorm Child Psychol 21(3):245-269

36. Costigan CL, Cox MJ (2001) Fathers' participation in family research: Is there a self-selection bias? J Fam Psychol 15(4): 706-720 